\title{
DE89 012281
}

\section{DESIGN CALCULATIONS AND MEASUREMENTS OE A DIPOLE MAGNET WTTH PEFMENDUR POLE PIECES'}

\author{
R. A. Early, J. K. CobB and J. E. Oujala \\ Stanford Linear Accelenator Center, Stanford Universily. Stanford, Caljforma 94909
}

\begin{abstract}
A redesign of the SLC Souch Linac-to-Ring beam line re. quired that the width of a good field of three of the bending magnets be increased while utilizing the same yoke und coils. Further requiresnents were that the resulting magnets should bave the same strength at two different operating eurrepts as the original magnets. The idea of replacing the steel poles with pole pieces of the high permeability material Permendur was inveatigated. Design calculations were done using TOSCA and POISSON. An existing prototype magnet was modified with Permendat poles, and magnetic measurements wese done. The new magnets were completed. and measurements agreed well with the calculations.

\section{INTRODUCTION}

The SLAC Collider South Sianc-to Ring beam line has been redesigned to incorporale an energy compresnor.' An increase in magnet aperture width was required at several points in the beam transport line. One of the requirements wat that the good ficld widib of three idestical beud magnets be esseatially dou. bled. There were several important const raints. The magnets would be wined in series with other un-altered bend mugnets and would have to achieve the same strength $\left(\int B_{y} d z\right)$ as these magnets at twa different energy settings. The original plan was to remove the magnets during a shul-down period and modify the poles. This meant that the new desiga would have to ueilize the old yoke and coils. Previous computer atudies on similiar magnets had shown that replacing the steel poles with Permendur would give an increase in cood field because of the high saturation induction properties of that mulerial. Because of the constiaints mentioned above and a critical time path, we decided to use this material. So lar a we know, previous mugnet designs utilizing this material have beed mainly for wiggter magnets and were relatively small in size. Our pole pieces were of the order of $2 \times 4 \times 12$ inches.
\end{abstract}

\section{PERMENDUR}

Petmendur, an alloy of steel and cobalt is equal propor. tions with about $2 \%$ vanadium, can normally be abtained in atmost any shape; howeter, only 4 inch rolled stoch was avail. able within six months. This material was obtuined and forged into blocks approximately $2.5 \times 4.5 \times 13$ inches. The forging was done at an estimated lemperature of $1040^{\circ} \mathrm{C}$, and the pieces were allowed to cool under ambient conditions. We followed an annealing procedure suggested by E. Hoyer of LBL." Values of intrinsic induction ( $\mathrm{B}-\mu_{\circ} H$ ) of 2.26 Tes) were messured af LBL (see Fig. 1). The B-H cune deviazes from the GE chart for Permendur, which is shown for reference. This may be due to beat treatment and/or chemical differences in the material. Our computatioss and measurements agree best when using the LBL Lable.

We were cautioned to do a serond anneal before final finish. ing. This second anneal caused the material to expand haterally about 0.005 iactes and to shrink about 0.020 inches is length. This may have been astrest relief process due to the forging.

\section{DESIGN CALCULATIONS}

Configuration for the magnets are shown in Figo. 2 and 3. These are $9^{\circ}$ bend magnets. Each pole end face is rotated $\pm 4.5^{\circ}$ about the $y$ axis so that the bearn enters and exits at right

\footnotetext{
+ Work supported by the Department of Energy. contract DEAC03-76SFO0SIL.
}

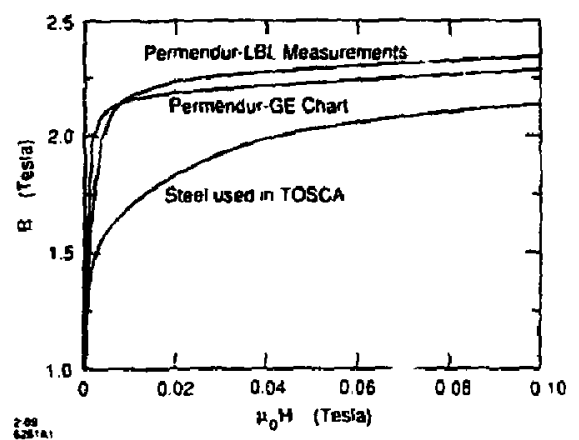

Fig. I. Gouph of $B$ ve. $H$.

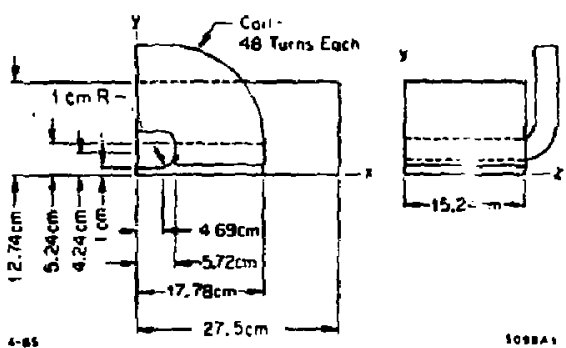

Fig. 2. Configunation for the new SLC SLTR bend magnets. angles to the pole face. The first computer siudics were done with POLSSON. Preriaus work bad shown that good field widits predicted by POISSON were too high by a factor of two when compared to measuretments of $\int B_{y} d z$ distribution for this type of magnet. TOSCA ${ }^{\prime}$ runs and measurements show that two. dimensional calculations are only good at the center of the mag. net. Even though the ratio of length-10-gap is about 15 for this magnet. it is highly suturated at the pole edges. The magnets were sequired to have a value of $f B, d z$ of 0.604 Teala-metess at a eurent of 355 amps for operation at $1.153 \mathrm{GeV}$. A value of 0.034 Teala-meters at 395 amps was required tor operation at $t .21 \mathrm{GeV}$. The good field required was $\pm 28 \mathrm{~mm}$ in $\times$ for a decrease of $\int B$ dz of $0.25 \%$. The good field for the original magaets was $\pm 15 \mathrm{~mm}$. The magnets mere made stranger by $0.9 \%$ to correct for measured loskes to aeighboring quadrupoles. Strength adjuntments were done by varying the length of the magnets with thin shimg locakd between the poles and the pole ends. A further adjustment can be mude by trim windings. This alows operation at two energies.

While simply replacing the steel poles with Permendur would increase the good field width, the resulting good field does bot meet that requised. A narrow pole with edge shimning was designed which did meet athe requirements, but this design was overruled in favor of a flat pole for simplicity of construction. A flat pole must be made wide, and the loss in efficiency crcalcs a 
problem with strength, since the current could not be increased. POISSON and TOSCA studies showed that atrength could be increased about $2 \%$ by recessing the pole picce into the oteel yole by $2 \mathrm{~cm}$. This was occomplished by andwiching the bese of the pole between two finely ground sted blocks. A equare pole end increased strength, but decreased the good field width. This was compensated by shaping the pole ends with a emall notch, or swallow-lail. TOSCA was quite uneful and accurate in studying such end effects.

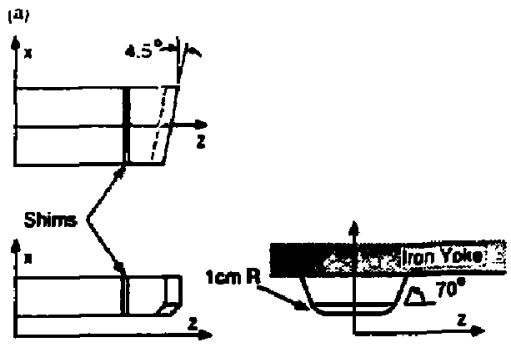

(b)

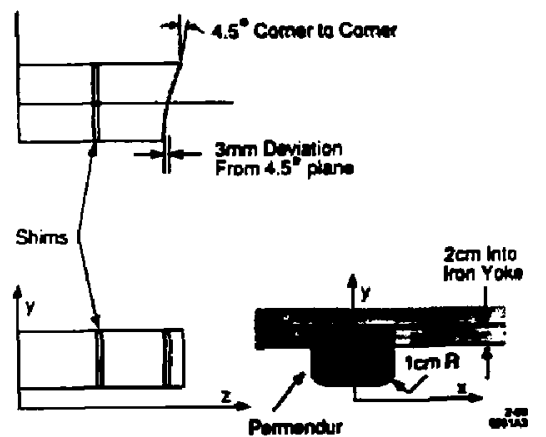

Fig. 9. Pole configurations for the old and new SLC SLTR Bend Magnets.

\section{MAGNETIC MEASUREMBNTS}

Two methods wert uned: (1) a moving Hall probe, and (2) an integrating long wire.

Moving probe mesuremeata were made uring a Hall probe digi al gausstueter with an IBEEA88 interface to a microcomputer. The probe wa eet on a precision lexd-serem crom-alide asembly so that the probe could be moved both along the lon. gitudinal axis (z) and the tranoverve axis $(x)$. Precision lead screwslides were driven by Slo-syn atepping motors controlled by two Carnac Stepping Motor Controlless (SMC) interfaced to 2 microcomputer. The magretic field it reagtb (IEEE digital gausemeter) and the excitation cumeat(IEEE digilal voll-metrr) were read each time the probe atopped moring is the $z$ direction. The meaturement sccuracy was epproximately $0.01 \%$ for the gavoumeter resdinge, and the excitation curnent veried lese than 0.001\% during each longtitudina nurvey. The precinion lead screws were accurate to within 5 microns. This method gave al accurate shape of the B-field in both $x$ and $z$ directions. Sorne resules of there mearurements are shomb in Figa. 1 and 5.

Integratiog long wire mesourcments were made uring a 10 . turn long wire (coil) that wa at retched through the magnet. The wire was moved in the transverse direction $(x)$ by two high precision atepping motos slides. The distance moved was read is well as the coil output in volt-econds (digital voltmeter) and recorded by a mitrocomp jter. The accuracy of this method was

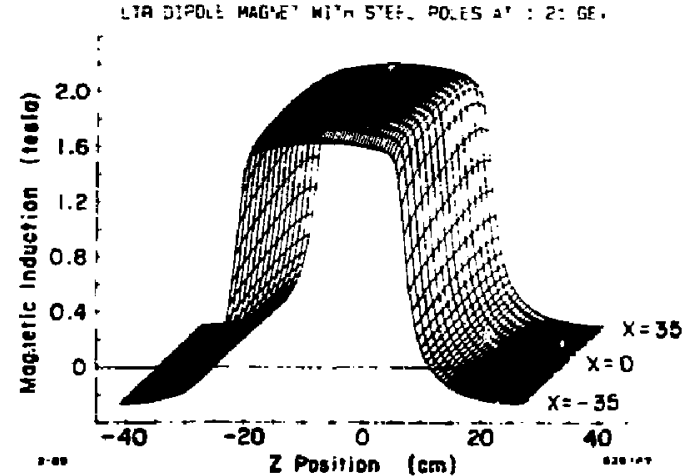

Fig. 4. $B_{y}$ Da. $z$ and $z$ for the original steal polc.

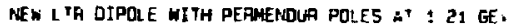

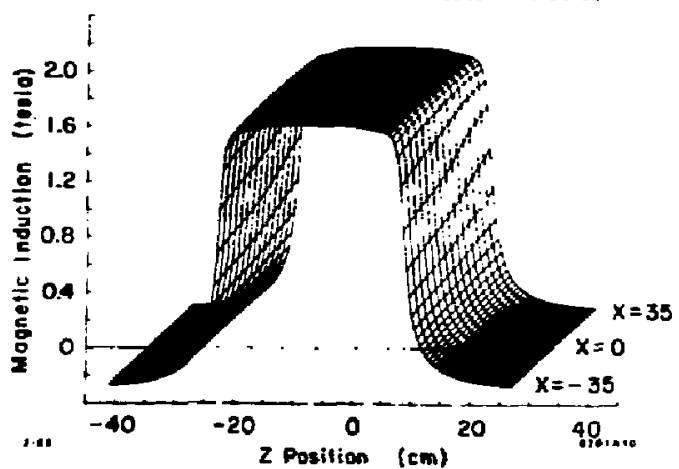

Fig. 5. $B$, a and a for the new permendur pole.

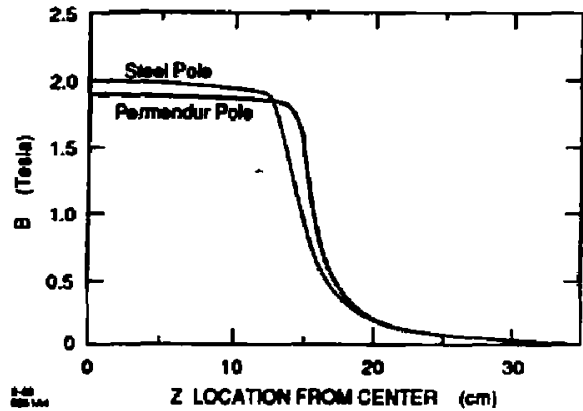

Fig. 6. $B$, as. I for the original ateel pole magnet and for the neo permendur pole megnet.

epproximately $0.03 \%$. This method was used for mearuring the absolute attength $\left(\int B, d z\right)$ at different transverse $(x)$ locations.

\section{RXSUITS}

The final mignets were witbin $0.1 \%$ of their required strength at $1.21 \mathrm{GeV}$ and bad good field regions of $\pm 32 \mathrm{~mm}$ in $x$ at $1.153 \mathrm{GeV}$ and $\pm 30 \mathrm{~mm}$ ot $1.21 \mathrm{GeV}$. The good field was defined as the vilue of $x$ where $\int B_{y} d z$ in down $0.25 \%$. The field distributions along the $z$ axis for both the new and old designs are given in $\mathrm{Fig}_{\mathrm{g}} \mathrm{f}$. Note that the Permendur pole runs at a lower value of $B_{1}$ at the center of the magnet, but bas a sharper edge. Hall probe measurements indicate that the conners of the 


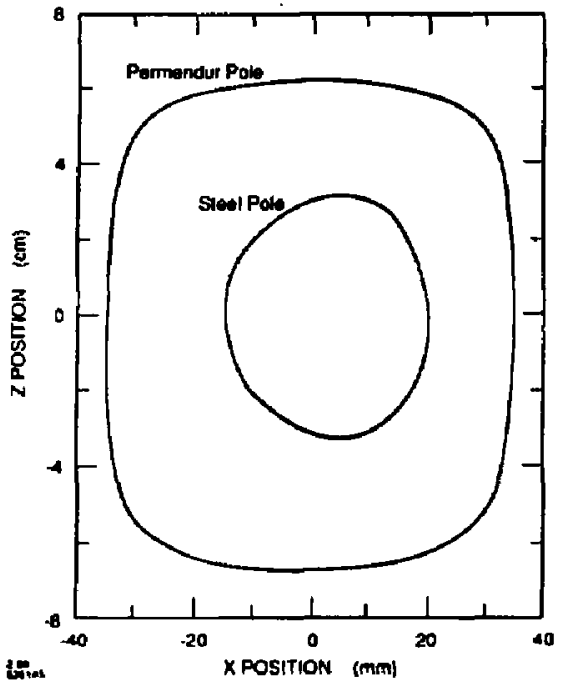

Fig. 7. Contours of $B_{y} / B_{0}$ of $99.75 \%$ for the sted pole and the permendur pole magmets.

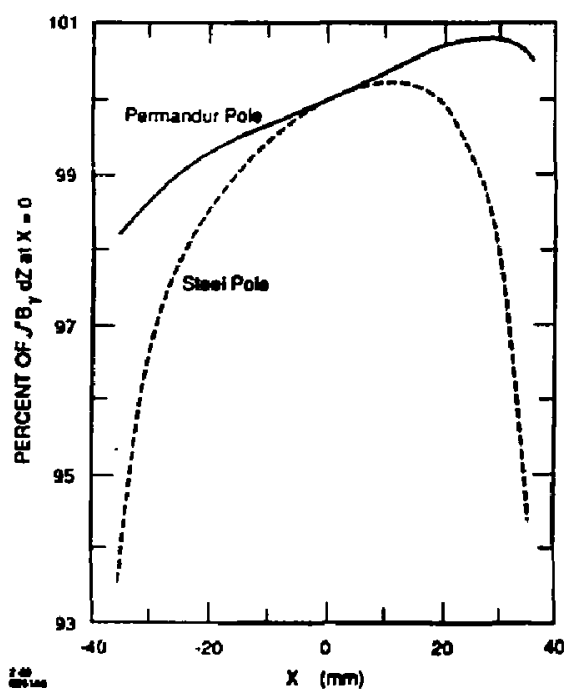

Fig. 8. $\int B_{p} d 2$ w. 2 at $1.21 \mathrm{GeV}$.

Permendur pole are running at fields above $2.3 \mathrm{Teal}$. $A$ comparison of good field contours ia given in Fis. 7 . The distortion in $x$ is due to the $4.5^{\circ}$ pole rotation. Figure 8 show the $\int B$, dz distributions accroas the magnet. The slopes are due to the pole-end rotations, and the slight dip in the ditribution for the new magaet is due to the swallow-tail correction. TOSCA runs. showed that higher order corrections are posaible, but they introduce unnecessary machining dificultion. If Fis. 9, we show

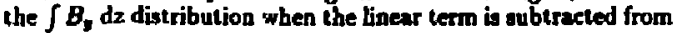
a fit to measurments. The excitation curves shown in Fis. 10 show that the Petmendur magnet is mose eficieat at low currents incause of the higher permesbility, while less efficient at high e srrents because of the wide, tat pole deaign. The differ. ences are made up by trim windinas.

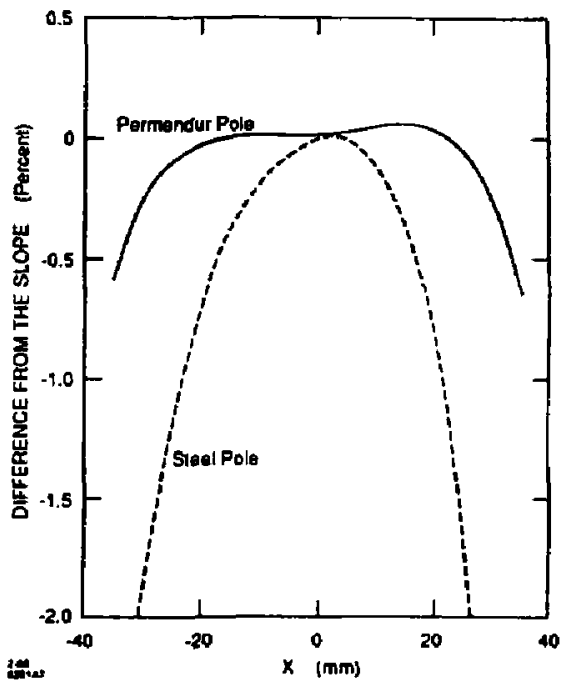

Fig. 9. $\int B_{\text {, dz }}$ t's. I with linear ferm subtrocted.

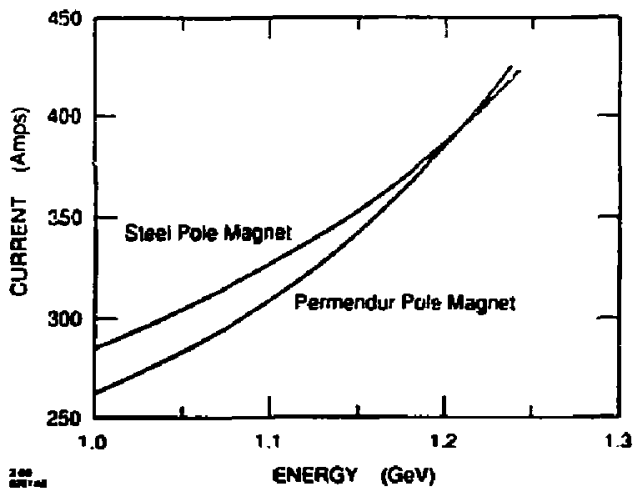

Fig. 10. Current os. energy setting for the sted pole and for the permendur pole magnets.

\section{ACKNOWLEDGMENTS}

TOSCA wa run on the NMFECC Criy 2 where version 4.0 has been installed by John Stewart of L,LNL. He has also written a non-interactive pre-processor. C. Perkins and b. Sukiennicki did the engineering for the prototype and for the final magnrt design. We are grateful to $\mathbf{E}$. Hoyer of LBL, and $\boldsymbol{H}$. Shich of BNL for information on Permendur.

\section{REFERENCES}

1. J. Clendenin et at., to be publisbed.

2. E. Hoyer, private communication.

3. D. Nelson and M. Green, Permeabulity Measurrments of Vanadium Permendur, LBL Engineering Note, 1982.

4. J. Simkin and C. W. Trowbridge, Thre-Dimensional Nonlinear Electromagnetır Field Calculations, Using Scalar Potentials, IEEE Proceedings, vol. 27. Pt. B. No. 6. November $19 \mathrm{so}$. 


\section{DISCLAIMER}

This report was prepared as an aceoust of work sponsored by an agency of the Unitad States Government. Neither the United States Government nor any ageacy thereof, nos any of their employees, makes any warrenty, express or implied, or assumes any legal liability or respomsibility for the accuracy, completeneas, or usefulness of any information, apparatus. product, of process diclowed, or represents that its use would not infringe privately owned rights. Reference herein to any specific commetcial product, procest, or service by trade matne, trademath. manufacturer, or otherwise does not necessurily constitute or imply ins endorsement. recommendation, or favoring by the Uniled States Govermment or any agency thereof. The views and opinions of authors expressed herein do not necescarily state of reflect these of the Uniled Stales Government or any agency thereof. 